\title{
The Resilience of Personality Disorders: The Possibile Change through an Integrated Approach
}

\section{Barbara Sartini*}

Università Cattolica del Sacro Cuore of Medicine, Rome, Italy

\section{Short Communication}

Personality disorders are diagnosed in $40-60 \%$ of psychiatric patients. Those with personality disorder manifested great difficulties in interpersonal relationships, unstable self-image, marked impulsitivity and so in dealing with everyday life.

Although the causes of the disorder are multifactorial, mainly, the common factors concern:

EID Emotional intensity disorder

- Hypersensitivity to life events

- Hyper emotional reactivity

- Slow return to a baseline psychic equilibrium

The peculiarity is the change of these types of personalities (EID personalities), so emotionally vulnerable, to resilient personalities. Resilience is the ability to cope effectively to everyday adversities, despite the past life's adverse and traumatic events. Research has shown that resilience is ordinary, not extraordinary. People commonly demostrate resilience. It is not a feature, that is present or absent in the individual, but, instead, refers to behaviors, thoughts and actions that can be learned by anyone. The old metaphor applies: resilient people are like bamboo in a hurricane-they bend rather than break. Or, even if they feel like they're broken for a time, there's still a part of them deep inside that knows they won't be broken forever. Here's how they do it...

\section{The Resilience Personality}

- The capacity to make realistic plans and take steps to carry them out.

- A positive view of yourself and confidence in your strengths and abilities.

- Keep good and supportive relationships.

- Have a menu of self-care habits (They have a mental list of good habits that support them when they need it most).

- Skills in communication and problem solving.

- The capacity to manage strong feelings and impulses.

In my job, I have been able to observe and verify how the sociotherapy approach in the therapeutic community [1] integrated with the STEPPS's training [2] can develop resilient personalities.

\section{The Sociotherapy}

- Introduces new possibilities for action entrusted to the patients themselves

- Highlights a number of strategies for the rehabilitation

- Allows the growth of the "healthy" part of the individual problematic.

Certainly the most significant event of this definition dates back to the "Therapeutic Community" by Maxwell Jones. It was based on a condition of perfect equality of the hospital institution's members.
The patient has an active role in the treatment. It promotes a dynamic and continuous relationship between individuals and between the individual and the community.

\section{Sociotherapy's Features and Strategies}

- Safety (Rules, agenda of groups and activities)

- Empowerment (make decisions)

- Living learning (improve yourself doing experience day by day)

- Emphaty (support and share emotions)

- Democracy (role blurring)

- Comunalism (share daily activities)

- Culture of enquiry (confront about each behavior)

\section{Steps Program}

The Iowa program began in 1995, based on a systems approach to treating individuals with Borderline Personality Disorder (BPD), originally developed by Bartels and Crotty [3-5]. That program was subsequently adapted and revised by Blum, St. John, and Pfohl [6-9] and has been further revised for this second edition.

The current program includes two phases: a 20 week basic skills group, and a one-year, twice monthly advanced group program called STAIRWAYS.

The basic format consist of 3 phases:

1. Awareness of Illness

2. Emotion Management Skills Training

3. Behavior Management Skills Training

This therapeutic and riabilititative integration allows to increase in the patients those skills necessary to resume positively the control of their lives, doing the individual experiences as:

- Relationships with caring and supportive people,

- Taking positions of responsibility (sociotherapy),

- Awareness of their strengths and weaknesses

- Learning of emotional management skills and problem solving (STEPPS).

*Corresponding author: Barbara Sartini, Università Cattolica del Sacro Cuore of Medicine, Rome, Italy, Fax: 3471177354; Tel: 393471177354; E-mail: sartinibarbara83@gmail.com

Received December 27, 2016; Accepted December 29, 2016; Published December 31, 2016

Citation: Sartini B (2016) The Resilience of Personality Disorders: The Possibile Change through an Integrated Approach. Int J Neurorehabilitation 3: 238. doi: 10.4172/2376-0281.1000238

Copyright: ( $) 2016$ Sartini B, et al. This is an open-access article distributed under the terms of the Creative Commons Attribution License, which permits unrestricted use, distribution, and reproduction in any medium, provided the original author and source are credited. 
Citation: Sartini B (2016) The Resilience of Personality Disorders: The Possibile Change through an Integrated Approach. Int J Neurorehabilitation 3: 238. doi: 10.4172/2376-0281.1000238

\section{References}

1. Maxwell J (1987) II processo di cambiamento. Nascita e trasformazione di una comunità terapeutica. FrancoAngeli, Milano.

2. Blum N, Black DW, St John D (2014) Systems Training for Emotional Predictability and Problem Solving (STEPPS). In: John C, Frank EY, Otto F (edr.) Kernberg, Psicoterapia delle personalità borderline. Raffaello Cortina, Milano.

3. John G (2003) La personalità borderline. Una guida clinica, Raffaello Cortina, Milano.

4. Livesley J, Larstone R (2014) Handbook of personality disorders: theory research and treatment. Guilford Publications, New York.
5. American Psychological Association (2014) The road to resilience. APA, USA.

6. Block JH, Block J (1980) The role of ego-control and ego-resiliency in the origination of behavior. In: Collings WA (edn.) The Minnesota Symposia on Child Psychology. NJ: Erlbaum, Hillsdale.

7. Cicchetti D, Rogosch FA, Lynch M, Holt KD (1993) Resilience in maltreated children: Processes leading to adaptive outcome. Development and Psychopathology, USA.

8. Yontef (1993) Awareness, dialogue, and process, essays on Gestalt therapy The Gestalt Journal Press, USA.

9. Kernberg OF (1987) Disturbi gravi della personalità. Bollati Boringhieri, Torino. 